\title{
Square-edge intraocular lenses and epithelial lens cell proliferation: implications on posterior capsule opacification in an in vitro model
}

\author{
Rita Mencucci ${ }^{1 *}$, Eleonora Favuzza ${ }^{1 \dagger}$, Carlotta Boccalini ${ }^{1 \dagger}$, Jean-Jacques Gicquel ${ }^{2 \dagger}$ and Laura Raimondi ${ }^{3+}$
}

\begin{abstract}
Background: To evaluate lens epithelial cell (LEC) proliferation with two different designs (one-piece or three-piece) of hydrophobic acrylic IOLs with $360^{\circ}$ square optic edge using an in vitro culture model of posterior capsule opacification (PCO).

Methods: This experimental study was conducted at the Department of NEUROFARBA, Section of Pharmacology, University of Florence, Italy. Human LECs were seeded and cultured in transwell cell culture inserts coated with a type-IV collagen membrane on which an IOL (one-piece Tecnis-1 or three-piece AR40E, Abbott Medical Optics Inc.) had been previously placed. As control, cells were plated on the insert membrane without an IOL. At day six (cells confluent in controls) IOLs were removed and cell counting, viability and cell density under and outside the IOLs were evaluated.
\end{abstract}

Results: No statistically significant difference in the number of cells ( $p>0.05$ ) between inserts with the one-piece and three-piece IOLs was found. Cell density in the area under each IOL was significantly lower than in the area outside of it $(p<0.05)$, or in the control insert. $(p<0.05)$. Cell density under the single-piece IOL was not significantly different from that under the three-piece IOL $(p>0.05)$.

Conclusions: $\mathrm{A} 360^{\circ}$ sharp-edge played a crucial role in avoiding LEC migration under the $\mathrm{IOL}$ and preventing the formation of PCO after cataract surgery. Long term clinical evaluation is necessary to estimate functional results.

Keywords: Posterior capsule opacification, Intraocular lens, Square edge, Cataract

\section{Background}

The proliferation and migration of residual lens epithelial cells (LECs) from the peripheral posterior capsular bag into the space between the capsule and the optic of the intraocular ocular lens (IOL) still remains a postoperative complication of modern cataract surgery. This phenomenon leads to anterior (ACO) and posterior capsule opacification (PCO) and decreased visual acuity [1,2]. Mechanical [3], pharmacological [4], immunological [5] and surgical factors [6] seem to be related to the presence of PCO after cataract surgery. Advances in intraocular lens (IOL) materials and design attempt to control some of these factors and to avoid PCO development as

\footnotetext{
* Correspondence: rita.mencucci@unifi.it

${ }^{\dagger}$ Equal contributors

'Department of Surgery and Translational Medicine - Eye Clinic, University of Florence, Florence, Italy

Full list of author information is available at the end of the article
}

much as possible. Hollick and colleagues [7] demonstrated several years ago that the presence of LECs on the posterior capsule after cataract surgery was considerably lower with polyacrylic IOLs than with poly(methyl methacrylate) (PMMA) or silicon IOLs. Indeed, in vitro studies have shown that the migration of human LECs under an acrylic IOL is reduced in comparison to PMMA and silicone IOLs [8]. Regarding IOL design, a sharp optic edge has been demonstrated to prevent migration of LEC between the capsular bag and the IOL $[8,9]$.

In spite of the slowing down or blocking of PCO development with square optic edges, there is still a relevant clinical evidence of PCO $[8,9]$ and consequently a considerable interest in developing in vitro models allowing the clinician to understand the mechanisms of LEC proliferation. Several in vitro models have been described, mainly based on lens capsular bag systems (organ models) 
[10-14]: although these models reproduce the human capsular bag-lens environment in the most accurate way, they are quite complex to carry out and the LEC proliferation and migration measurements can be scarcely reproducible due to the high interindividual variability of the ex vivo lens capsule characteristics [15]. On the contrary, in vitro cell culture models [15-18] can be more easily set up.

Animal studies [19] post-mortem analysis [20] and clinical evidence [21] showed that the square-edge interruption at the optic-haptic junction typical of most of the one-piece acrylic IOLs (the so-called Achilles' heel of these IOLs) [22] can increase the incidence and the severity of PCO in comparison with a continuous posterior square-edge. Recently, a hydrophobic acrylic one piece IOL with a 360-degree square edge (Tecnis-1 ZCB00, Abbott Medical Optics Inc, USA) was introduced in Europe, and some authors found a lower incidence of PCO in eyes implanted with these IOLs compared with interrupted square-edge one-piece IOLs [2]. The aim of our study was to evaluate LEC proliferation and migration with a 360-degree square-edge one-piece IOL (Tecnis-1 ZCB00 from AMO) and a square-edge three-piece IOL (AR40E from AMO) using an in vitro cell culture model.

\section{Methods}

The experiments were performed following the tenets of the Declaration of Helsinki.

\section{Cell culture}

In this study, human LECs were used (B-3 cell line), which were obtained from the American Type Culture Collection (ATCC, Manassas, VA, USA). The cells were maintained in culture medium consisting of Dulbecco's modified Eagle's medium (DMEM, Sigma-Aldrich, St. Louis, MO, USA), 20\% fetal bovine serum (FBS, SigmaAldrich, St. Louis, MO, USA), $100 \mathrm{U} / \mathrm{mL}$ penicillin G, $100 \mu \mathrm{g} / \mathrm{mL}$ streptomycin (Sigma-Aldrich, St. Louis, MO, USA), sodium pyruvate (1:50), L-glutamine (1:100), in a humidified atmosphere of $5 \% \mathrm{CO}_{2}$ at $37^{\circ} \mathrm{C}$.

\section{Intraocular lenses (IOLs)}

The two types of IOLs (Tecnis ZCB00 and AR40E from AMO) evaluated in the current study are made of the same hydrophobic acrylic material, have a 6-mm biconvex optic, an overall diameter of $13 \mathrm{~mm}$ and a continuous 360-degree posterior square edge to prevent PCO. The Tecnis ZCB00 is a one-piece IOL with aspheric anterior surface and offset haptics, made of the same material as the optic, whereas the AR40E is a three-piece IOL with PMMA angulated haptics (5-degree angle). Both IOL models are produced via lathe-cutting by the same manufacturer. For the purpose of the study, 10
IOLs of the same optical power (+20 Diopters) were selected for each type of design.

\section{PCO in vitro model}

The PCO model previously described by Gotoh et al. [16] was used for our experimental research. Each IOL $(n=20)$ was placed on a cell culture insert coated with $5 \mu \mathrm{g} / \mathrm{cm}^{2}$ type IV collagen (BD Biosciences, San Jose, CA) in a 12-well culture plate to simulate the formation of $\mathrm{PCO}$ after cataract surgery with the implantation of an IOL.

A tiny aluminium weight $(0.85 \mathrm{~g})$ [16] was placed on the IOL to maintain contact between the IOL and the collagen membrane. Cells $\left(10^{4}\right)$ were seeded into each culture transwell and incubated in $700 \mu \mathrm{l} 20 \%$ FBS/DMEM. Collagen membrane inserts without IOL $(\mathrm{n}=10)$ were considered as controls.

\section{Proliferation assay: cell counting and viability}

After 6 days (when the cells incubated without IOL reached confluence), the cells present in the whole insert were detached by trypsinization and counted with the trypan blue exclusion test. Cell viability was evaluated throughout the oxidation by the mitochondrial chain of 3[4,5-dimethylthiazol-2yl]-2,5-diphenyltetrazolium bromide (MTT) to insoluble formazan. The formazan production after $2 \mathrm{~h}$ was evaluated colorimetrically at $590 \mathrm{~nm}$, in terms of optical density (OD) [23].

\section{Proliferation assay: cell density}

At day 6 (when the cells incubated without IOL reached confluence), cells were fixed with $100 \%$ methanol and stained with hematoxylin-eosin. Cells present in six independent zones (under and outside the IOL) were photographed and counted using an inverted-phase microscope (TMS, Nikon Instruments Europe BV, Netherlands).

Mean values from cell counting were determined using a $21 \mathrm{~mm}^{2}$ grid (Figure 1).

\section{Statistical analysis}

Calculations were made using GraphPad Prism and Instat version 4.0 for Windows (GraphPad Software, San Diego, CA, USA) was used for statistical analysis. Results for each IOL and the control model were the mean \pm SD of at least 5 experiments run in duplicate. The Wilcoxon Rank Sum test was applied to assess the comparisons between cell counting and density for each IOL and the control model, using in all cases the same level of significance $(\mathrm{p}<0.05)$.

\section{Results}

\section{Cell counting and viability}

Figure 2 shows the changes over the period of culture in the cell counting for each IOL as well as for the control inserts. As shown, the cell number in inserts containing 

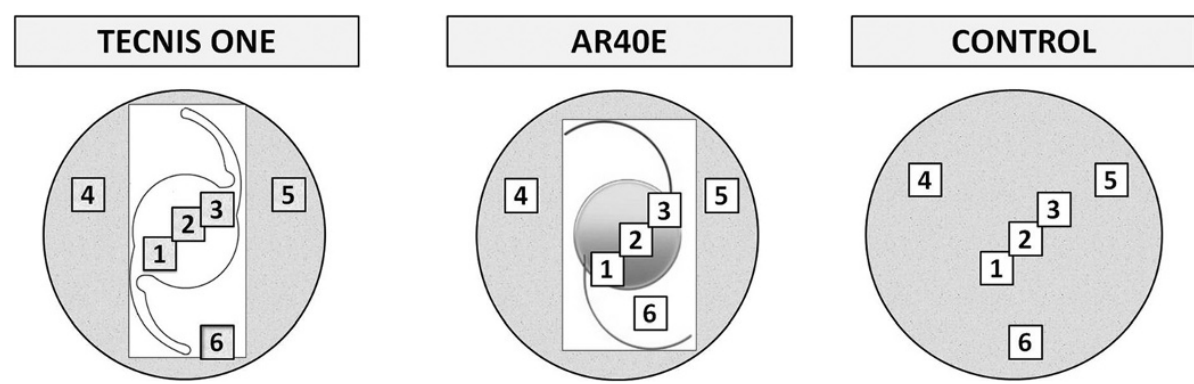

Figure 1 Diagram showing the experimental procedure for the evaluation of the cell density in the proliferation assay.

IOLs was significantly lower $(\mathrm{p}<0.05)$ at day 6 than that in controls. In contrast, no statistically significant difference was found in the number of cells contained in the inserts with the Tecnis ZCB00 and AR40E IOLs ( $p>0.05)$. Regarding cell viability, the optical density at $590 \mathrm{~nm}$ after the MTT test was $0.208 \pm 0.050$ in controls, $0.123 \pm 0.010$ in Tecnis- 1 inserts and $0.116 \pm 0.012$ in AR40E inserts. All cells present in each insert were viable.

\section{Cell density}

Figure 3 summarizes the results of the cell density test at day 6 for each IOL, as well as for the control insert. As shown, cell density in the area under each IOL was significantly lower than that found outside of it $(\mathrm{p}<0.05$, Figure 3). Likewise, cell density was significantly higher in the control insert compared to those containing the IOLs $(\mathrm{p}<0.05$, Figure 3$)$. Cell density under the Tecnis ZCB00 IOL was not significantly different from that under the AR40E IOL ( $p>0.05$, Figure 3).

In microscopic images (Figure $4 \mathrm{~A}, \mathrm{~B}$ and $\mathrm{C}, 4 \mathrm{X}$ ), cells were shown to concentrate at the square-edge barrier (Figure $4 \mathrm{~B}$ and $\mathrm{C}$ ), with low migration of cells under the IOL (Figure 4B and C). Furthermore, the analysis of the microscopic photographs revealed the importance of the $360^{\circ}$ square edge to avoid cell migration at the optichaptic junction (Figure 4C).

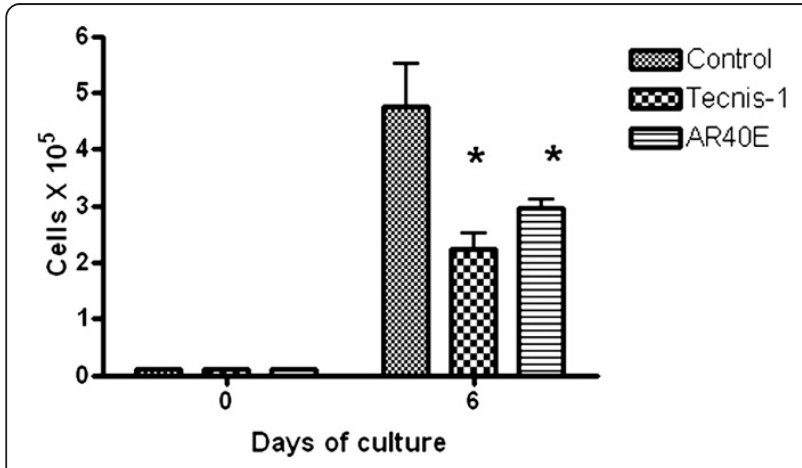

Figure 2 Cell number counting during the 6-day period of culture. ${ }^{*} p<0.05$ vs Control at day six.

\section{Discussion}

The present study shows that in our experimental conditions a $360^{\circ}$ sharp optic edge acts as an effective barrier to LEC migration.

Similarly, Kurosaka and colleagues [15] found in another in vitro study that an acrylic sharp-edge IOL and a PMMA IOL with similar edge design inhibited LEC migration more effectively than silicone and PMMA rounded-edge IOLs. This is consistent with the clinical evidence reported $[2,8,9]$. Specifically, Nixon and Woodcock found in a comparative study between eyes implanted with continuous-edge and interrupted edge IOLs that the mean EPCO (software for the Evaluation of Posterior Capsule Opacification) score was significantly higher for eyes with the interrupted-edge IOL compared to the $360^{\circ}$ squareedge ( 0.39 vs. $0.08, \mathrm{p}=0.012)$ [2]. On the contrary, other authors showed similar incidence of PCO in eyes implanted with interrupted square-edge IOLs, in comparison with $360^{\circ}$ square-edge IOLs [24]. Anyway, even if this concept is still under debate, a sharp uninterrupted optic edge can be considered an important factor in preventing PCO formation.

In the last years the researchers' interest towards in vitro PCO models that allow the study of PCO cellular mechanisms and potential prevention factors is rising. Human lens epithelial cell behaviour in different

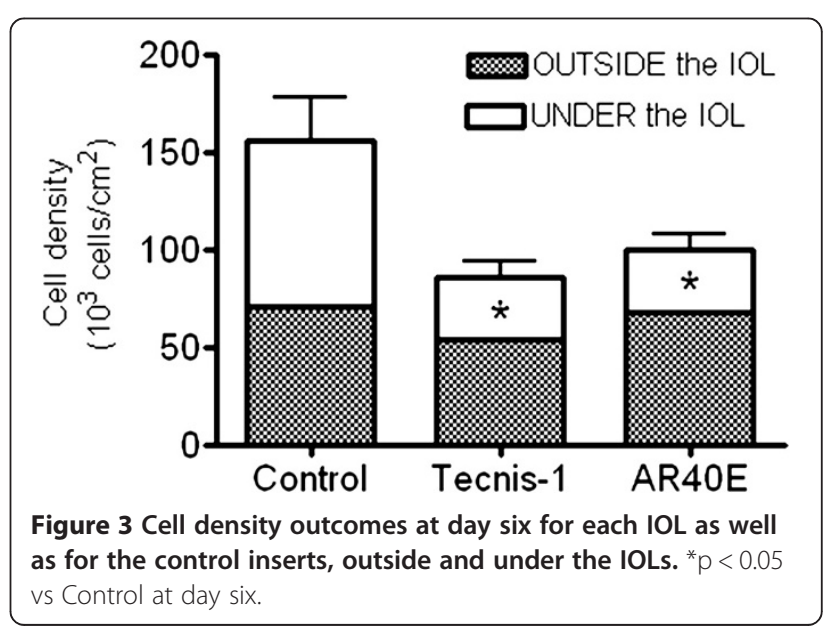



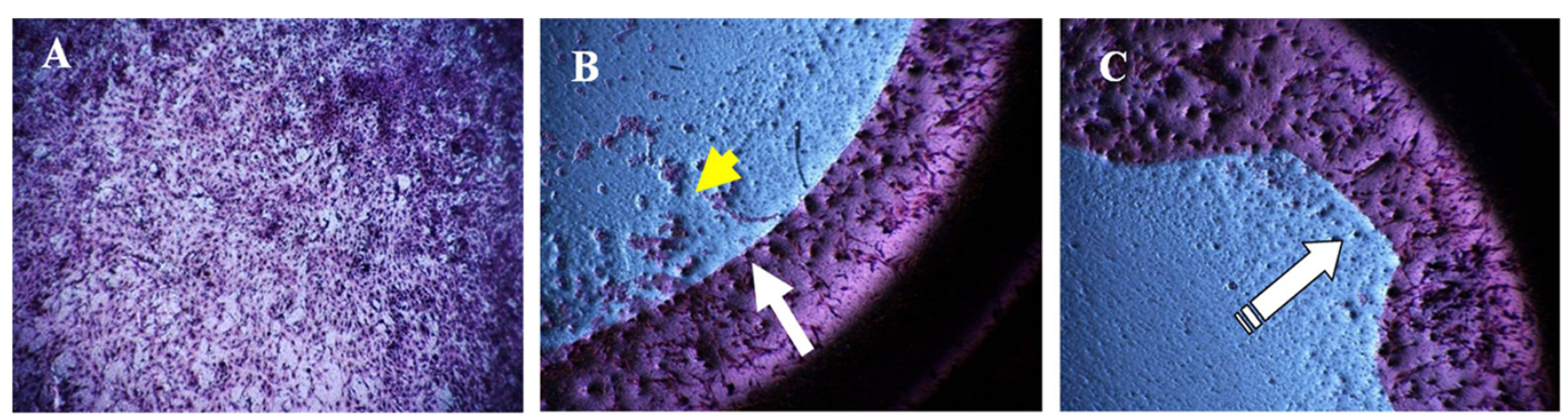

Figure 4 Lens Epithelial Cells on transwell collagen membrane after IOL removal, cell fixation and hematoxylin-eosin staining (4X). A) Control: cell confluence at day 6. B) AR40E insert: clear separation between cells under the IOL and those beyond the optic square-edge barrier. C) Tecnis-1 insert: Cell migration at the optic-haptic junction prevented by the $360^{\circ}$ sharp optic edge.

experimental conditions, with media containing different protein or growth factor concentrations has indeed been deeply studied [10]. The capsular bag organ models use animal or human lens capsule, isolated from donor eyes after sham cataract surgery with or without an intraocular lens implantation [10-14]. Various methods have been described in order to support the capsular bag during culture: external fixation of the capsule to the culture dish using glue [13] or entomological pins [10,14], the fixation of the ciliary body [11], or internal capsule expansion using Capsular Tension Rings (CTRs) [12]. The main limitations of these models are the potential obscuration of the view of the equatorial area and the interference with LEC migration (CTRs models), a possible distortion of the capsular shape, the forced apposition of the posterior and the anterior capsule and potential capsule tears formation ("pin models") [11]. Moreover, LECs from individuals of different ages and characteristics can have different growth pattern and behaviour, affecting the reproducibility of the model [15].

In vitro cell culture models, on the other hand, try to reproduce the capsular bag system using transwell inserts coated with bovine [15], Type I or Type IV collagen membrane [16,17], or PMMA Petri dish [18], on which an IOL can be placed and LECs (immortalized cell lines or primary/secondary cultures) can be seeded and cultured. These materials are commercially available and are easy to handle.

They have been successfully used in previous studies evaluating different aspects of PCO formation [15-17]. Kurosaka et al. [15] studied how acrylic and others IOLs influence LEC migration, concluding that acrylic IOLs inhibited LEC migration by not only a sharp edge but also other factors, such as adhesive properties of the material. Okajima and coauthors [17] evaluated the effect of coating a hydrophobic acrylic IOL with poly(2-methacryloyloxyethyl phosphorylcholine) (MPC) on LEC migration, showing that this coating suppressed adhesion and proliferation of LECs.
We used the in vitro model described by Gotoh and colleagues [16]. This model was originally developed to examine the effect of matricellular protein SPARC (secreted protein, acidic and rich in cysteine) and transforming growth factor (TGF)- $\beta$ on PCO [16].

One of the most important parameters that can affect the evaluation of LEC behaviour and growth pattern in in vitro culture models in the presence of different IOLs, is the difficulty in reproducing the forces that act in vivo on the IOL keeping it in contact with the posterior capsule. Tetz and Wildeck [18] tested and compared different weights of various materials on IOLs placed on a culture dish, concluding that a silver weight of $0.7 \mathrm{~g}$ was able to fix the IOL without blocking cell growth under it and causing no cell reaction. Gotoh et al. [16] used instead an aluminium weight of $0.85 \mathrm{~g}$, that in our experimental condition was able to give stability to the IOL without causing cell death or reaction.

Anyway also in the organ models the apposition between the anterior and the posterior capsule is a crucial factor and can vary between the different models [11].

The main advantage of in vitro cell culture models is their acceptable reproducibility in the same experimental conditions. The Gotoh model allowed us to compare easily the LEC behaviour in presence of IOLs with different designs.

Nevertheless, it should be considered that this model, such as all the available in vitro models of PCO, is not able to fully reproduce the complex environment of the capsular bag-lens system. Moreover, the influence of the anterior capsule and haptic angulation on $\mathrm{PCO}$ are not taken into account.

In our study we found a significant difference between the number of cells present in the area outside the IOLs and under the IOLs, suggesting a barrier effect of the posterior sharp edge of the optic of both IOL types. In the transwells with the Tecnis-1 IOL, the cell migration under the optic-haptic junction, generally considered a weak point of the edge barrier of the single-piece IOLs, 
was minimized by the peculiar design that guarantees a continuous posterior sharp-edge. This offset haptic design allows for a $360^{\circ}$ sharp optic edge preventing LEC migration. Additionally cell migration is prevented by the 3 point fixation (TriFix design) which pushes the lens against the posterior capsular bag and keeps it in a secure position.

Clinical studies [2] showed not only a low rate of PCO but also a relatively good centration and rotational stability of this 1-piece design, which again is supported by the 3 -point fixation that allows a sustained contact between the IOL and the posterior capsule [25].

\section{Conclusions}

In conclusion, our experimental results suggest that a $360^{\circ}$ IOL sharp optic edge is a crucial factor to avoid LEC migration and therefore the formation of PCO after cataract surgery. Furthermore, a similar behaviour in inhibiting LEC migration is present in a single-piece and a threepiece IOL with 360-degree optic edge design and comparable material properties. Long term clinical evaluation is necessary to investigate functional results, development of PCO and the influence of the anterior capsule and of the haptic angulation in these two IOL models.

\section{Competing interests}

None of the authors have any competing interests to declare.

\section{Authors' contributions}

RM: conceived the study, participated in its design and coordination, helped in performing the experiments, drafted and revised the manuscript. EF: performed the experiments, analysed the data, drafted and revised the manuscript. CB: performed the experiments, analysed the data, drafted and revised the manuscript. JJG: conceived the study, participated in its design and coordination, drafted and revised the manuscript; LR: conceived the study, participated in its design and coordination, performed the experiments, analysed the data, drafted and revised the manuscript. All authors read and approved the final manuscript.

\section{Author details}

${ }^{1}$ Department of Surgery and Translational Medicine - Eye Clinic, University of Florence, Florence, Italy. ²Department of Ophthalmology, Poitiers University Hospital, Poitiers, Cedex, France. ${ }^{3}$ Department of NEUROFARBA, section of

Pharmacology, University of Florence, Florence, Italy.

Received: 24 July 2014 Accepted: 10 January 2015

Published: 19 January 2015

\section{References}

1. Vasavada AR, Raj SM, Shah A, Shah G, Vasavada V, Vasavada V. Comparison of posterior capsule opacification with hydrophobic acrylic and hydrophilic acrylic intraocular lenses. J Cataract Refract Surg. 2011;37:1050-9.

2. Nixon DR, Woodcock MG. Pattern of posterior capsule opacification models 2 years postoperatively with 2 single-piece acrylic intraocular lenses. J Cataract Refract Surg. 2010;36:929-34.

3. Peng Q, Visessook N, Apple DJ, Pandey SK, Werner L, Escobar-Gomez M, et al. Surgical prevention of posterior capsule opacification. Part 3: intraocular lens optic barrier effect as a second line of defense. J Cataract Refract Surg. 2000;26:198-213.

4. Chung HS, Lim SJ, Kim HB. Effect of mitomycin-C on posterior capsule opacification in rabbit eyes. J Cataract Refract Surg. 2000;26:1537-42.

5. Meacock WR, Spalton DJ, Hollick EJ, Boyce JF, Barman S, Sanguinetti G. Double-masked prospective ocular safety study of a lens epithelial cell antibody to prevent posterior capsule opacification. J Cataract Refract Surg. 2000;26:716-21.
6. Apple DJ, Peng Q, Visessook N, Werner L, Pandey SK, Escobar-Gomez M, et al. Surgical prevention of posterior capsule opacification. Part 1: progress in eliminating this complication of cataract surgery. J Cataract Refract Surg. 2000;26:180-7.

7. Hollick EJ, Spalton DJ, Ursell PG, Pande MV. Lens epithelial cell regression on the posterior capsule with different intraocular lens materials. $\mathrm{Br}$ J Ophthalmol. 1998;82:1182-8.

8. Kohnen T, Fabian E, Gerl R, Hunold W, Hütz W, Strobel J, et al. Optic edge design as long-term factor for posterior capsular opacification rates. Ophthalmology. 2008;115:1308-14. 1314.e1-3.

9. Findl O, Menapace R, Sacu S, Buehl W, Rainer G. Effect of optic material on posterior capsule opacification in intraocular lenses with sharp-edge optics: randomized clinical trial. Ophthalmology. 2005;112:67-72.

10. Dawes $\amalg$, Illingworth CD, Wormstone I. A fully human in vitro capsular bag model to permit intraocular lens evaluation. Invest Ophthalmol Vis Sci. 2012;53:23-9.

11. Cleary G, Spalton DJ, Zhang JJ, Marshall J. In vitro lens capsule model for investigation of posterior capsule opacification. J Cataract Refract Surg. 2010;36:1249-52.

12. Burger J, Kreutzer T, Alge CS, Strauss RW, Eibl K, Haritoglou C, et al. Capsular tension ring-based in vitro capsule opacification model. J Cataract Refract Surg. 2008;34:1167-72.

13. El-Osta AA, Spalton DJ, Marshall J. In vitro model for the study of human posterior capsule opacification. J Cataract Refract Surg. 2003;29:1593-600.

14. Liu CS, Wormstone IM, Duncan G, Marcantonio JM, Webb SF, Davies PD. A study of human lens cell growth in vitro. A model for posterior capsule opacification. Invest Ophthalmol Vis Sci. 1996;37:906-14.

15. Kurosaka D, Obasawa M, Kurosaka H, Nakamura K. Inhibition of lens epithelial cell migration by an acrylic intraocular lens in vitro. Ophthalmic Res. 2002;34:29-37.

16. Gotoh N, Perdue NR, Matsushima H, Sage EH, Yan Q, Clark Jl. An in vitro model of posterior capsular opacity: SPARC and TGF-beta2 minimize epithelial-to-mesenchymal transition in lens epithelium. Invest Ophthalmol Vis Sci. 2007:48:4679-87.

17. Okajima Y, Saika S, Sawa M. Effect of surface coating an acrylic intraocular lens with poly(2-methacryloyloxyethyl phosphorylcholine) polymer on lens epithelial cell line behavior. J Cataract Refract Surg. 2006;32:666-71.

18. Tetz M, Wildeck A. Evaluating and defining the sharpness of intraocular lenses. Part 1: influence of optic design on the growth of the lens epithelial cells in vitro. J Cataract Refract Surg. 2005;31:2171-9.

19. Nishi O, Nishi K, Osakabe Y. Evaluation of posterior capsule opacification using a new posterior view method in rabbits. Single-piece acrylic versus 3-piece acrylic intraocular lens. J Cataract Refract Surg. 2005;31:2369-74.

20. Ness PJ, Werner L, Maddula S, Davis D, Zaugg B, Stringham J, et al. Pathology of 219 human cadaver eyes with 1-piece or 3-piece hydrophobic acrylic intraocular lenses: capsular bag opacification and sites of square-edged barrier breach. J Cataract Refract Surg. 2011;37:923-30.

21. Nixon DR, Apple DJ. Evaluation of lens epithelial cell migration in vivo at the haptic-optic junction of a one-piece hydrophobic acrylic intraocular lens. Am J Ophthalmol. 2006;142:557-62.

22. Werner $L$, Mamalis $N$, Izak AM. Posterior capsule opacification in rabbit eyes implanted with 1-piece and 3-piece hydrophobic acrylic intraocular lenses. J Cataract Refract Surg. 2005;31:805-11.

23. Mosmann T. Rapid colorimetric assay for cellular growth and survival: application to proliferation and cytotoxicity assays. J Immunol Methods. 1983;65:55-63.

24. Buehl W, Findl O. Effect of intraocular lens design on posterior capsule opacification. J Cataract Refract Surg. 2008;34:1976-85.

25. Roshdy MM, Riad RF, Morkos FF, Hassouna AK, Wahba SS. Effect of a single-piece aspheric hydrophobic acrylic intraocular lens design on centration and rotation. J Cataract Refract Surg. 2013;39:408-13.

\section{doi:10.1186/1471-2415-15-5}

Cite this article as: Mencucci et al:: Square-edge intraocular lenses and epithelial lens cell proliferation: implications on posterior capsule opacification in an in vitro model. BMC Ophthalmology 2015 15:5. 